\title{
Reliability Allocation Method of Production Line Based on Fuzzy Comprehensive Evaluation
}

\author{
Guofa $\mathrm{Li}^{1, \mathrm{a}}$, Chao Hou${ }^{1, \mathrm{~b}}$, Guofei Liü,c, Yuhui Jia ${ }^{1, \mathrm{~d}}$,Chang $\mathrm{Liu}^{2, \mathrm{e}}$,Jinghua \\ Dong $^{1, f}$ \\ ${ }^{1}$ School of Mechanical Science \& Engineering ,Jilin University, Changchun 130022, China \\ ${ }^{2}$ The Pan Asia Technical Automotive Center, Pudong New Area, Shanghai 201201, China

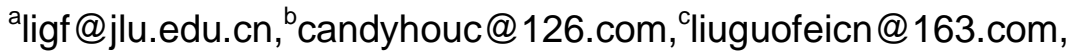

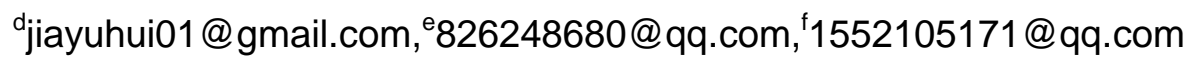

\begin{abstract}
Keywords: Production Line, Reliability Allocation, Fuzzy Comprehensive Evaluation, Redundancy Optimization Design
\end{abstract}

\begin{abstract}
A fuzzy comprehensive evaluation model was built to allocate the reliability of production line combined with the actual case studies. The production rate was converted to inherent availability in the calculation. Considering the buffer, we corrected the allocation index. Combined the opinion of relevant staff and experts, determined various types of factors and right weight that effect reliability of production line. Finally, simulated the production line and optimized allocation results. Provided allocation strategy to production lines.
\end{abstract}

\section{Introduction}

Currently, scholars gradually realized that we should prevent failures from the root, reliability allocation methods for CNC machine tools and systems are becoming increasingly mature. Internationally, it has accumulated a large number of academic achievements about reliability allocation methods of the system. Including genetic algorithms, dynamic programming, deterministic algorithms, etc. ${ }^{[1]}$ Yang, etc ${ }^{[2]}$ use these algorithms combine reliability allocation in

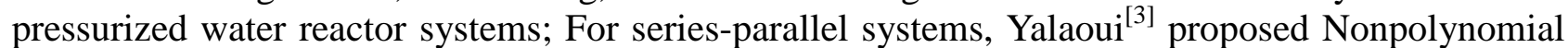
Dynamic Programming; Mettas ${ }^{[4]}$ developed Blocksim software program which can optimize reliability allocation method for large complex systems. ITEM company and Siemens AG have developed software on system reliability allocation. Enterprises can use the production site-related data complete the modeling and simulation of complex production line ${ }^{[5-7]}$.

Major universities also developed software on reliability design, which mainly include: CARMES developed by CEPREI; ARMS developed by Kewill Venture technology company, that mainly used in system reliability design research of aerospace, shipbuilding, electronics and other industries ${ }^{[8]}$.

Although methods for system reliability allocation have been more mature, the research for actual production lines are relatively few. Since structures of automated production lines are complex, dynamic performance is outstanding, it is difficult to get the correct allocation result while using a single method. Therefore, this article use statistic ,fuzzy mathematics and other related knowledge, give the final result taking the specific structure of production line and buffer into account. Finally, simulated the production line and optimized allocation results.

\section{Reliability Allocation Model of Production line}

Index of Reliability Allocation. There are multiple evaluation indexes of production line, which mainly include: overall equipment efficiency, allocation efficiency, production rate, output and so on. The production rate $(K)$ is a key indicator widely recognized by companies, it is similar to the reliability inherent availability $(A)$, there are slight differences in time division.

Production rate directly determines the output and efficiency of the production line, so most companies are pursuing high production rate. Production rate is decided by output, beat and 
configuration time, the specific relationship is shown as follows:

$$
K=\frac{\text { take time } \times \text { output }}{\text { configuration time }}
$$

If the production line is in the design stage, it is unable to count on its output, so we can not get accurate statistics of production rate. Inherent availability $(A)$ can be used to instead production rate:

$$
A=\frac{M T B F_{s}}{M T B F_{s}+M T T R_{s}}
$$

$M T B F_{S}$ means time between failures of production line, $M T T R_{S}$ means time to repair of production line.

From what we have discussed above, inherent availability is determined by $\mathrm{MTBF}_{\mathrm{s}}$ and $\mathrm{MTTR}_{\mathrm{s}}$, production rate is determined by output and configuration time. While these periods have a certain overlap, thus we need to divide the entire additional time. Suppose the percentage of production time (excluding the non-operating time of equipment, loss of production time) is $\mathrm{p}_{1}$, the percentage of configuration time is $\mathrm{p}_{2}$, therefore, we can obtain the following equation:

$$
K=\frac{M T B F_{s} \times p_{1}}{\left(M T B F_{s}+M T T R_{s}\right) \times p_{2}}
$$

Factors of Reliability Allocation. Fuzzy Comprehensive Evaluation factors will directly affect the results of reliability allocation, therefore, after discussing with the business experts and staff, we decided to take frequency of failures, average repair time, equipment importance, equipment complexity, technical level and working environment as factors of Fuzzy Comprehensive Evaluation.

(1)Frequency of failures

For equipments that always fail, herein may see them as weaknesses in production line. The higher the score is , the lower reliability value should be.

(2)Average repair time

Average repair time means the length of time that production line can not work, in the condition of inherent availability is determined, the longer the repair time is, the lower the value is.

(3)Equipment importance

The more important, complicated process equipment assumes, its importance is higher.

(4)Equipment complexity

For complex production equipment, the assigned reliability indicators should be lower.

(5)Technical level

Researchers need to rely on market research, count production equipments that have high technical level and assign them a higher reliability index.

(6)Working environment

Most of the equipment are in the same external environment, but due to equipment have different processing technology, their processing environment are very different. In view of this, we make working environment an important index.

The Correction of Reliability Allocation Index While Considering Buffer. We can obtain frequency of failures and average repair time by historical data:

$$
\mathrm{MTBF}_{s}=\frac{1}{N_{0}} \sum_{i=1}^{n} t_{i}=\frac{\sum_{i=1}^{n} t_{i}}{\sum_{i=1}^{n} r_{i}}
$$

$t_{i}$ means the cumulative operating time of i-th production unit in the cycle;

$r_{i}$ means the cumulative number of associated failures of i-th production unit in the cycle;

$N_{0}$ means the cumulative number of associated failures of the production unit in the cycle;

$\mathrm{n}$ means Number of samples in the cycle;

In order to facilitate the calculation and considerate the role of buffer, suppose each time a failure 
occurs, WIP in buffer before faulty unit can supply half of maximum buffer time, there are:

$$
\begin{array}{r}
t_{f i}=t_{r i}-t_{s i} / 2 \\
M T T R_{s}=\frac{\sum_{i=1}^{n} t_{f i}}{\sum_{i=1}^{n} r_{r i}}
\end{array}
$$

$t_{s i}$ means maximum buffer time of i-th production unit;

$t_{r i}$ means cumulative repair time of i-th production unit in the cycle(unit: $h$ ) ;

$r_{r i}$ means the cumulative number of associated failures of i-th production unit in the cycle;

Fuzzy Comprehensive Evaluation Model. Reliability allocation method of production line with Fuzzy Comprehensive Evaluation can be divided into five steps:

(1) The establishment of factors set

A collection established by influential factors is called the factors set. These factors have considerable ambiguity in varying degrees. Establish relevant factors set has these factors: $U=\left\{u_{1}, u_{2}, \mathrm{~L}, u_{n}\right\}$, where $\mathrm{n}$ is the number of influential factors.

(2) The establishment of weight set

The influence levels of various factors are different, we can obtain a weight set $\stackrel{\mathrm{W}}{\mathrm{W}}=\left(w_{1}, w_{2}, \mathrm{~L}, w_{n}\right)$ the factors need normalization process.

(3) The establishment of evaluation set

Evaluation set $\stackrel{\circ}{V}=\left(v_{1}, v_{2}, \mathrm{~L}, v_{m}\right)$ is obtained by dividing grade of each factors, $\mathrm{m}$ is the number of results. According to the opinions of experts, determine the evaluation results of each factor.

(4) The establishment of evaluation matrix

First, determine the membership degree of relative evaluation set judging from a single factor. Then determine the evaluation matrix $\stackrel{\circ}{R}=\left(r_{i j}\right)_{n \times m}$ according to the established evaluation set and evaluation result of each single factor ,matrix factor $r_{i j}$ means when selecting assessment factor $u_{i}$, the membership degree of the assessment result $v_{j}$ of evaluation set.

(5) The Fuzzy Comprehensive Evaluation

After getting the above set and matrix, in accordance with $\stackrel{B}{=}=\stackrel{\circ}{W}$ o $\stackrel{R}{R}$, seeking evaluation index $b_{j}$. In the calculation of evaluation model, synthesis operator " $\mathrm{o}$ ” has the following algorithm:

(1) Use $(+, \times)$ composite operator, have $b_{j}=\sum_{i=1}^{n}\left(w_{i} \cdot r_{i j}\right)$

(2) Use $(\vee, \times)$ composite operator, have $b_{j}=\underset{i=1}{\vee}\left(w_{i} \cdot r_{i j}\right)$

(3) Use $(\vee, \oplus)$ composite operator, have $b_{j}=\oplus_{i=1}^{n}\left(w_{i} \wedge r_{i j}\right)$

(4) Use $(\vee, \wedge)$ composite operator, have $b_{j}=\stackrel{n}{\vee} \underset{i=1}{\vee}\left(w_{i} \wedge r_{i j}\right)$

It need normalization process after getting the fuzzy results. According to the ratio between weight and allocation index, obtain the following formula:

$$
\mathrm{MTBF}_{i}=\frac{\sum_{i=1}^{n} B_{i}}{B_{i}} \times \mathrm{MTBF}_{s}
$$

We can have allocate result $M T B F_{i}$ of each device in production line according to the above formula(unit: $h$ ). 


\section{Case Study}

Reliability allocation results. An enterprise has a crankshaft production line, try to use reliability allocation method make production rate reach $85 \%$, determine the reliability of each device. Wherein maximum time of each buffer is 30 minutes.

Production line layout shown in Figure 1. Some equipment rarely fail, such as: online testing platform, quenching, tempering unit, etc. Therefore, this article does consider such equipment. Data of approximate production line are shown in table 1:

Table 1 failure data of approximate production line

\begin{tabular}{cccccc}
\hline Production equipment & $\begin{array}{c}\text { number of } \\
\text { failures }\end{array}$ & $\begin{array}{c}\text { number of } \\
\text { equipment }\end{array}$ & $\begin{array}{c}M T B F \\
\text { /h }\end{array}$ & $\begin{array}{c}\text { MTTR/ } \\
\text { min }\end{array}$ & $A$ \\
\hline Face Milling Machine & 25 & 3 & 647 & 127 & 0.9967 \\
Quality Centering Machine & 13 & 4 & 950 & 102 & 0.9982 \\
Double-pole CNC & 35 & 4 & 612 & 145 & 0.9961 \\
Milling CNC & 66 & 3 & 250 & 226 & 0.9852 \\
Link CNC Lathes & 28 & 3 & 409 & 93 & 0.9962 \\
Hole Machining CNC & 44 & 4 & 451 & 98 & 0.9964 \\
Rolling Machines & 22 & 2 & 405 & 169 & 0.9931 \\
CNC Turret Lathe & 35 & 4 & 509 & 121 & 0.9961 \\
Crankshaft Grinding & 28 & 5 & 794 & 140 & 0.9971 \\
CNC Cylindrical Grinder & 66 & 4 & 335 & 129 & 0.9936 \\
Gear Heating Machine & 9 & 2 & 581 & 107 & 0.9969 \\
Multifunction Machining Center & 47 & 4 & 382 & 114 & 0.9951 \\
Remove Weight Machine & 21 & 3 & 525 & 120 & 0.9962 \\
Balancing Machine & 27 & 4 & 748 & 126 & 0.9972 \\
Oil Duct Cleaning Machine & 21 & 3 & 657 & 114 & 0.9971 \\
Polishing Machine & 99 & 3 & 182 & 88 & 0.9920 \\
Final Cleaning Machine & 30 & 2 & 396 & 128 & 0.9946 \\
Manipulator & 55 & 15 & 723 & 93 & 0.9979 \\
\hline
\end{tabular}

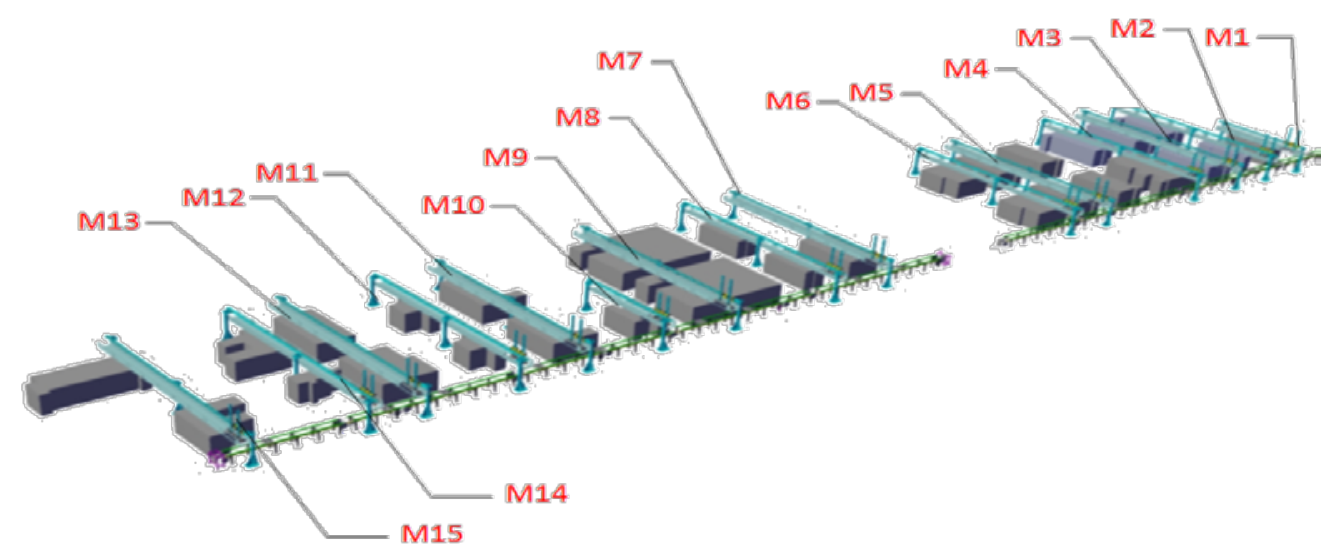

Fig. 1 Production line equipment layout (M1-M15 is production unit)

Since output in the cycle is unknown, turn indicators into the inherent availability. In a week, attendance time is 112 hour, additional time is shown as follows:

Table 2 Additional time

\begin{tabular}{lc}
\hline Time Categories & Specific Values \\
\hline Break Time (in a week) & $3.5 \mathrm{~h}$ \\
Education Time (in a week) & $0.5 \mathrm{~h}$ \\
Security Management (in a week) & $0.5 \mathrm{~h}$ \\
Trade Union Activities (in a week) & $0.5 \mathrm{~h}$ \\
Production Samples (in a week) & $0.5 \mathrm{~h}$ \\
Others (in a week) & $0.5 \mathrm{~h}$ \\
\hline
\end{tabular}


$P_{1}=90 \%, P_{2}=95 \%$ by calculation, the inherent availability $\mathrm{A} \approx 0.9$ obtained by equation 3,this value is reliability allocation indicator of the crankshaft production line. $M T T R_{S} \approx 2.585 \mathrm{~h}$ obtained by equation $6 . M T B F_{S} \approx 24 \mathrm{~h}$ obtained by equation 2 .

(1)Determine the factors and weight set

Factors and weight set is $\stackrel{\circ}{W}=\left(w_{1}, w_{2}, w_{3}, w_{4}, w_{5}, w_{6}\right)=(0.2,0.2,0.2,0.2,0.1,0.1)$ according to the opinion of scene operator and experts.

(2)The establishment of evaluation set

Range evaluation factors, specific division levels and standard are shown in Table3. Specific division results of importance, complexity, technical level and working environment are shown in Table4. This paper brings the suggestions of workers, maintenance staff, minister of equipment, data acquisition, etc together, obtained the final results shown in Table 5 after repeated calculation.

Table 3 Division Standard of Membership Range of Each Factor

\begin{tabular}{|c|c|c|c|c|c|c|}
\hline \multirow{2}{*}{$\begin{array}{l}\text { Divided } \\
\text { grade }\end{array}$} & \multicolumn{3}{|c|}{ Frequent of failure } & \multicolumn{3}{|c|}{ Time to repair } \\
\hline & Description & \multicolumn{2}{|c|}{ Membership range } & Description & \multicolumn{2}{|c|}{ Membership range } \\
\hline 1 & A lot & \multicolumn{2}{|c|}{ More than 16} & Very long & \multicolumn{2}{|c|}{ More than 210min } \\
\hline 2 & More & \multicolumn{2}{|c|}{$13-16$} & Long & \multicolumn{2}{|c|}{ 150-210min } \\
\hline 3 & General & \multicolumn{2}{|c|}{$9-12$} & General & \multicolumn{2}{|r|}{ 90-150min } \\
\hline 4 & Less & \multicolumn{2}{|r|}{$5-8$} & Short & \multicolumn{2}{|r|}{ 30-90min } \\
\hline 5 & Seldom & \multicolumn{2}{|r|}{$0-4$} & Very short & \multicolumn{2}{|r|}{$0-30 \mathrm{~min}$} \\
\hline \multicolumn{7}{|c|}{ Table 4 Membership Range of Each Factor } \\
\hline \multirow{2}{*}{$\begin{array}{l}\text { Divided } \\
\text { grade }\end{array}$} & \multicolumn{3}{|c|}{ Importance } & \multicolumn{3}{|c|}{ Complexity } \\
\hline & Description & \multicolumn{2}{|c|}{ Membership range } & Description & \multicolumn{2}{|c|}{ Membership range } \\
\hline 1 & Very low & \multicolumn{2}{|c|}{$[8-10]$} & Very high & \multicolumn{2}{|r|}{ [8-10] } \\
\hline 2 & Low & & $6-8)$ & High & & {$[6-8)$} \\
\hline 3 & General & & $4-6)$ & General & & {$[4-6)$} \\
\hline 4 & High & & 2-4) & Low & & {$[2-4)$} \\
\hline 5 & Very high & & $0-2)$ & Very low & & {$[0-2)$} \\
\hline Divided & & ical le & & Machin & ing enviro & onment \\
\hline grade & Description & Mem & rship range & Description & Men & mbership range \\
\hline 1 & Very low & & $3-10]$ & Very bad & & [8-10] \\
\hline 2 & Lower & & $6-8)$ & Bad & & {$[6-8)$} \\
\hline 3 & General & & $4-6)$ & General & & {$[4-6)$} \\
\hline 4 & Higher & & 2-4) & Good & & {$[2-4)$} \\
\hline 5 & Very high & & $0-2)$ & Very good & & {$[0-2)$} \\
\hline & & ble & coring Res & of Factors & & \\
\hline number & Machine $\mathrm{n}$ & & Importance & Complexity & $\begin{array}{c}\text { Technical } \\
\text { level }\end{array}$ & $\begin{array}{l}\text { Machining } \\
\text { environment }\end{array}$ \\
\hline 1 & Manipulat & & 5 & 2 & 2 & 2 \\
\hline 2 & Face Milling $\mathrm{N}$ & chine & 4 & 5 & 4 & 4 \\
\hline 3 & Manipulat & & 3 & 2 & 2 & 2 \\
\hline$\ldots$ & & & $\cdots$ & $\cdots$ & $\cdots$ & ? \\
\hline 38 & Manipulato & & 2 & 2 & 2 & 2 \\
\hline 39 & Polishing $\mathrm{M}_{\mathrm{c}}$ & & 4 & 3 & 6 & 8 \\
\hline 40 & Final Cleaning & achine & 4 & 4 & 3 & 3 \\
\hline
\end{tabular}

(3) The establishment of evaluation set

Establish evaluation matrix $\stackrel{\circ}{R}_{i}(i=1,2,3, \ldots, 40)$, and $\stackrel{\circ}{R}_{i}=\left(r_{i j}\right)_{6 \times 5}$. According to $\stackrel{\circ}{B}_{i}=\stackrel{\circ}{W}$ o $\stackrel{\circ}{R}_{i}$, calculated evaluation index $\stackrel{\circ}{B}_{i}$. This article select $(+, \times)$ synthesis operator, get the weighted rank of the production equipment. Each rating reviews set is $\widetilde{V}=(10,8,6,4,2)$.Get the corresponding evaluation results through $\mathrm{B}=\widetilde{\mathrm{B}}_{l}{ }^{\circ} \widetilde{\mathrm{V}}^{\mathrm{T}}$. According to the formula 7 , we may have allocation results of 
various production equipment:

$M_{T B F_{i}}=(1170,849,1303,1019,822,1303$ ， 822,1303 , 633, 822 , 1303 , 865 , 865 , 1303 , 793 , 1170 , 740 , 1303 , $849,849,1303$, 862 , 1381 , 703 , $951,951,1303,762,1303,703,703,1303,910,872,1303$, 1373 , $980,1381,721,849)$

Simulation and Optimization. We use Plantsimulation software predict the inherent availability of production line:

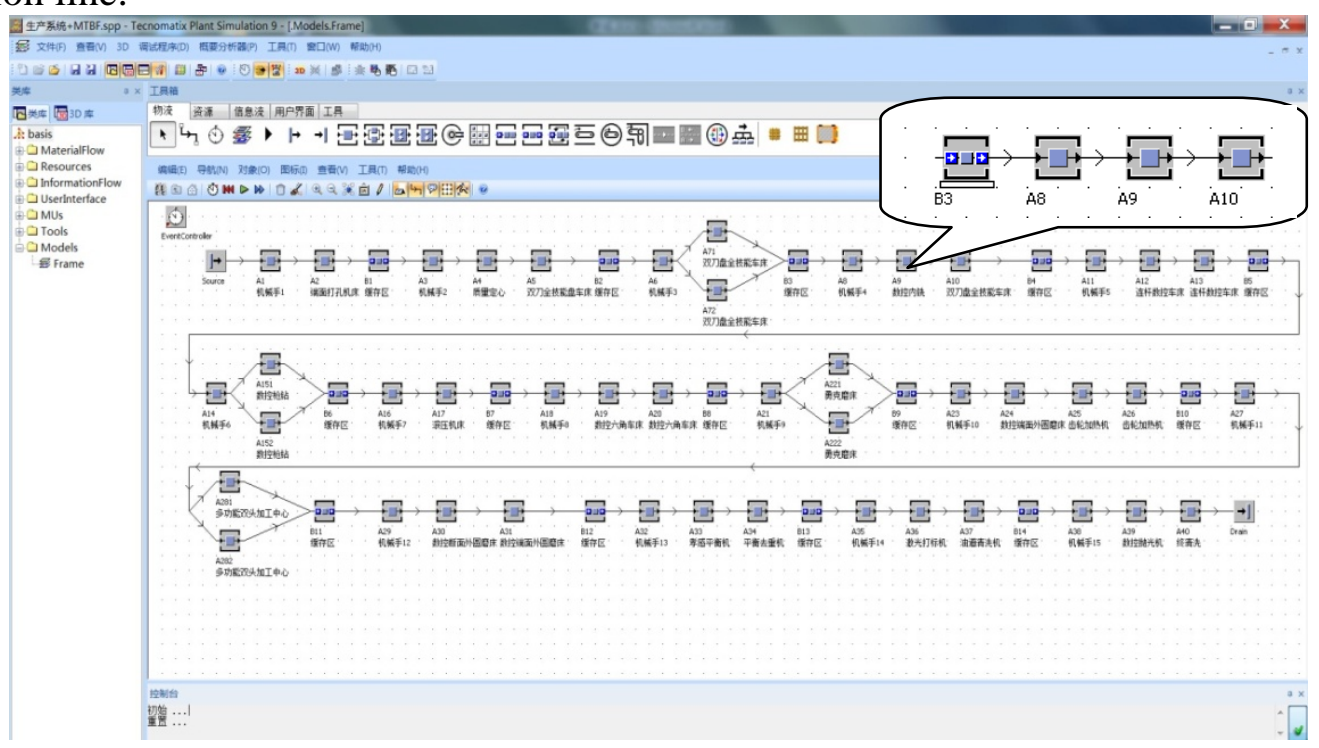

Fig. 1 Simulation of crankshaft production line

From simulation results, inherent availability is greater than $90 \%$,production rate is greater than 85\%. This paper addresses optimization problems for the equipment which have great differences between the target MTBF and practical MTBF(via discussion, the subtracted is greater than 400 hours), the specific content are shown in Table 6:

Table 6 the target value contrast to current level

\begin{tabular}{cccc}
\hline Machine name & $\begin{array}{c}\text { Target value } \\
(\mathrm{h})\end{array}$ & $\begin{array}{c}\text { Track record value } \\
(\mathrm{h})\end{array}$ & $\begin{array}{c}\text { Subtracted value } \\
(\mathrm{h})\end{array}$ \\
\hline Link CNC Lathes & 865 & 409 & 456 \\
Polishing Machine & 721 & 182 & 539 \\
Final Cleaning Machine & 849 & 396 & 453 \\
\hline
\end{tabular}

For equipment in Table 6, we can select the appropriate redundancy optimization method. In the case of not affect the production rhythm, ensure the normal operation of the system. In the view of above results, we can take MTBF of system as reliability of unit, index of single device as individual reliability, get related redundancy number:

Table 7 Number of equipment redundancy

\begin{tabular}{ccc}
\hline Machine name & Number of redundancy & Optimized \\
\hline Link CNC Lathes & 1 & 818 \\
Polishing Machine & 2 & 536 \\
Final Cleaning Machine & 1 & 792 \\
\hline
\end{tabular}

Redundant equipment also increase the cost. Thus, according to the actual need of manufacturers, we can increase or decrease the redundant equipment. 


\section{Conclusion}

In this paper, a method of system reliability allocation applied to the actual production line, and binding the effect of buffer, amended the allocation indicators. It has great significance to companies. Through research, draw the following conclusions:

(1) Turn output rate indicator into inherent availability, taking the role of buffer into account, get MTBF of the equipment.

(2) Use Plantsimulation software verify the result of allocation, and further suggest improvements. Use passive redundant design to equipment that unable to meet the requirement.

Due to time constraints, this study failed to resolve some of the problems. In order to fully take the role of buffer into account, we need record the number of workpiece and location of the buffer while each time a failure occurs, facilitate further study.

\section{References}

[1] Da Silva L. G.W, Pereira R A F, Mantovani J.R .S. Optimized Allocation of Sectionalizing Switches and Control and Protection Devices for Reliability Indices Improvement in Distribution Systems[C] , IEEE/PES Transmission \&Distribution Conference \& Exposition: Latin America, 2004:1-6.

[2] Yang J E, Hwang M J, Sung T Y, et al. Application of Genetic Algorithm for Reliability Allocation in Nuclear Power Plants[J]. Reliability Engineering and System Safety, 1999, 65: 229 238.

[3] Yalaoui J E, Chadtelet E, Chu C B.A New Dynamic Programming Method for Reliability \&Redundancy Allocation in a Parallel-Series System [J]. IEEETransactions on Reliability2005, 54(2): 254 - 262.

[4] Adamantios M. Reliability Allocation and Optimization for Complex Systems [C]//Proceedings Annual Reliability and Maintainability, 2000:216-222.

[5] Yin P Y, Yu S S, Wang P P, et al. Task Allocation for Maximizing Reliability of a Distributed System Using Hybrid Particle Swarm Optimization[J]. The Journal of Systems and Software, 2007(80):724 - 735.

[6] Huang C Y, Lo J H, Kuo S Y, et al. Optimal Allocation of Testing-Resource Considering Cost, Reliability, and Testing-Effort[C]//Proceedings of the $10^{\text {th }}$ IEEE Pacific Rim International Symposium on Dependable Computing, 2004.

[7] Chen T C. IAs Based Approach for Reliability Redundancy Allocation Problems [ J ]. Applied Mathematics and Computation, 2006(182): 1556 - 1567.

[8] Xiao Tianyuan, Fan Wenhui. Modeling and Simulation of Discrete Event System [M]. Electronic Industry Press, 2011.8: 254-255. 